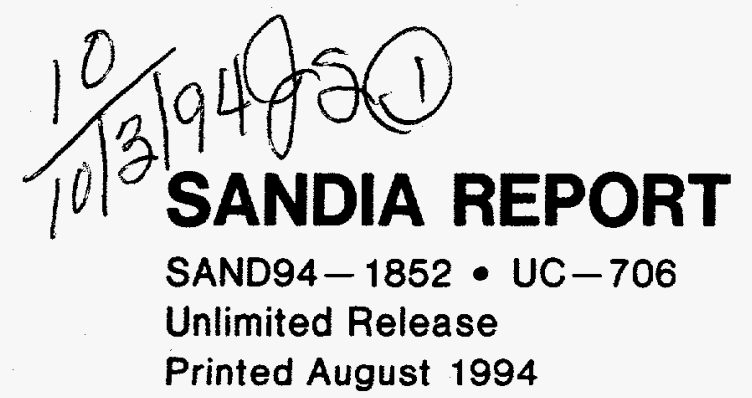

\title{
Nevada Test Site Closure Program
}

\author{
Dale P. Shenk
}

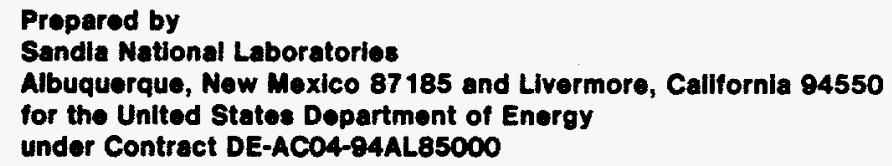

Approved for public release, distribution is unlimited.

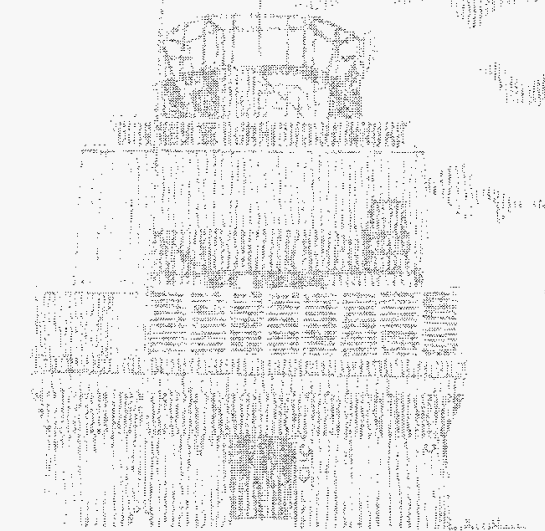


Issued by Sandia National Laboratories, operated for the United States Department of Energy by Sandia Corporation.

NOTICE: This report was prepared as an account of work sponsored by an agency of the United States Government. Neither the United States Government nor any agency thereof, nor any of their employees, nor any of their contractors, subcontractors, or their employees, makes any warranty, express or implied, or assumes any legal liability or responsibility for the accuracy, completeness, or usefulness of any information, apparatus, product, or process disclosed, or represents that its use would not infringe privately owned rights. Reference herein to any specific commercial product, process, or service by trade name, trademark, manufacturer, or otherwise, does not necessarily constitute or imply its endorsement, recommendation, or favoring by the United States Government, any agency thereof or any of their contractors or subcontractors. The views and opinions expressed herein do not necessarily state or reflect those of the United States Government, any agency thereof or any of their contractors.

Printed in the United States of America. This report has been reproduced directly from the best available copy.

Available to DOE and DOE contractors from Office of Scientific and Technical Information

PO Box 62

Oak Ridge, TN 37831

Prices available from (615) 576-8401, FTS 626-8401

Available to the public from

National Technical Information Service

US Department of Commerce

5285 Port Royal RD

Springfield, VA 22161

NTIS price codes

Printed copy: A03

Microfiche copy: A06 


\section{DISCLAIMER}

Portions of this document may be illegible in electronic image products. Images are produced from the best available original document. 


\title{
Nevada Test Site Closure Program
}

\author{
FAC \\ Fast Acting Closure \\ GSAC \\ Gas Sealing Auxiliary Closure \\ MAC \\ Modified Auxiliary Closure \\ STAC \\ Stemming Anchor Closure
}

Dale P. Shenk

Engineering Projects and Explosives Applications

Sandia National Laboratories

Albuquerque, New Mexico 87185-1156

\begin{abstract}
This report is a summary of the history, design and development, procurement, fabrication, installation and operation of the closures used as containment devices on underground nuclear tests at the Nevada Test Site. It also addresses the closure program mothball and start-up procedures. The Closure Program Document Index and equipment inventories, included as appendices, serve as location directories for future document reference and equipment use.
\end{abstract}





\section{Contents}

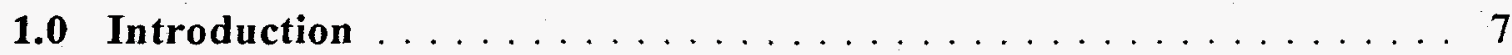

1.1 Document Purpose . . . . . . . . . . . . . . . . 7

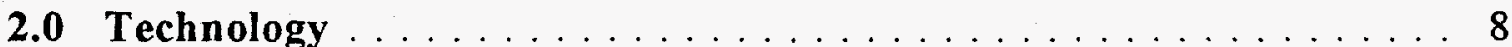

2.1 History . . . . . . . . . . . . . . . . . 8

2.2 Research and Development ................. 8

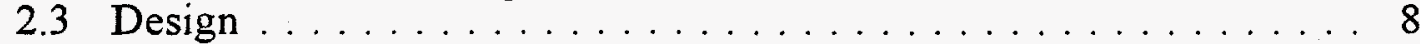

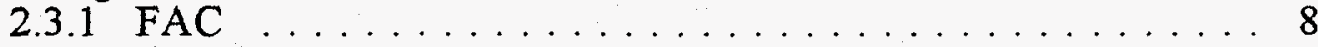

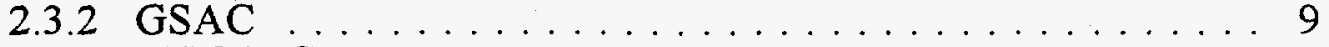

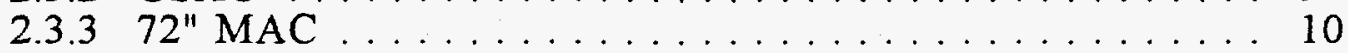

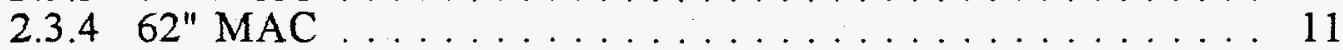

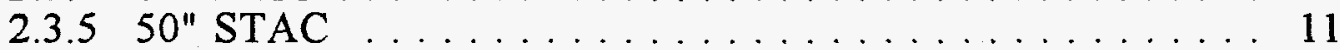

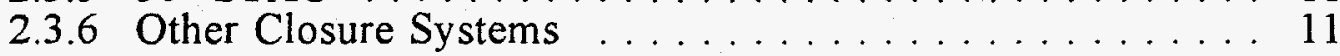

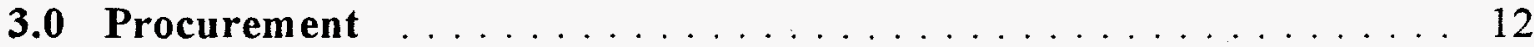

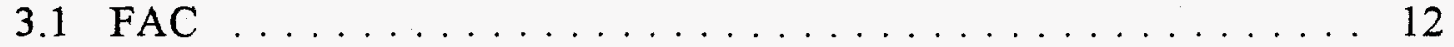

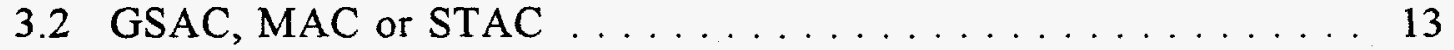

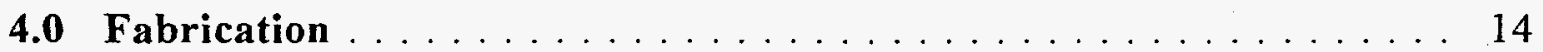

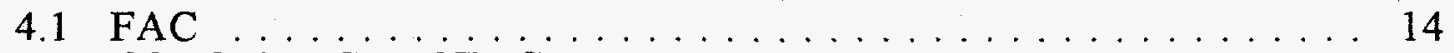

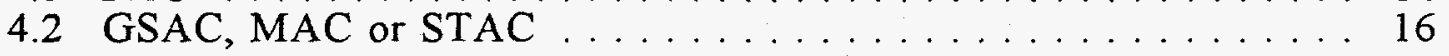

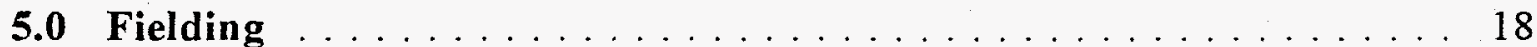

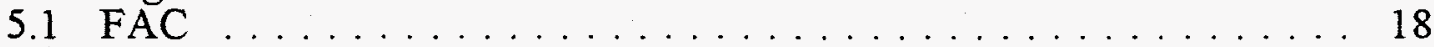

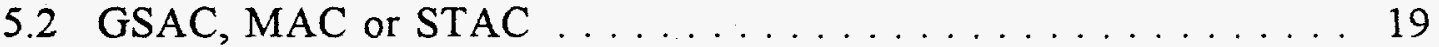

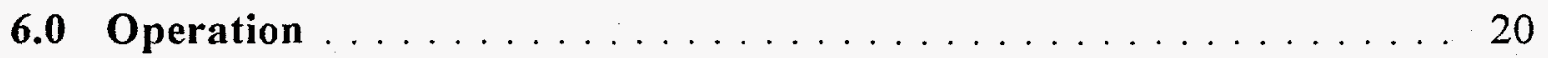

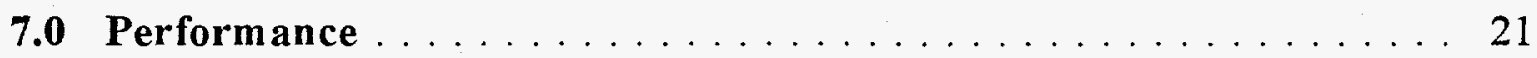

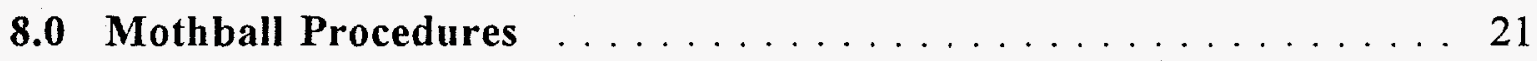

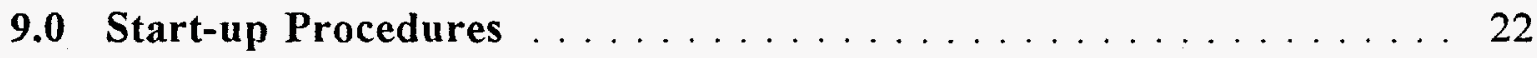

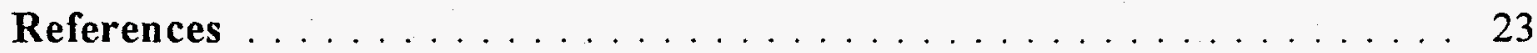

Appendix A Document Index $\ldots \ldots \ldots \ldots \ldots \ldots \ldots \ldots$

Appendix B FAC Equipment and Hardware Inventory . . . . . . . . . . 27

Appendix C Auxiliary Closure Equipment and Hardware Inventory . . . . 31

Figure 1. $30-$ inch Fast Acting Closure . . . . . . . . . . . . . 9

Figure 2. 72 -inch Gas Sealing Auxiliary Closure . . . . . . . . . . . . 10

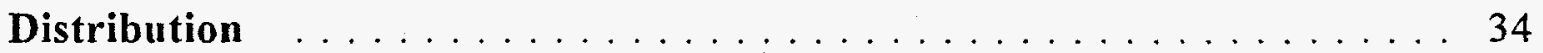





\section{Nevada Test Site Closure Program}

\subsection{Introduction}

The Sandia National Laboratories (SNL), Engineering Projects and Explosives Applications Department 9333 is responsible for the design, fabrication, assembly, testing, fielding and operation of several types of pipe closures used on Defense Nuclear Agency (DNA) sponsored underground nuclear tests. These closures are installed in the horizontal line-of-sight (HLOS) pipe of underground test beds at the Nevada Test Site (NTS). The closures' primary function, upon event detonation, is to rapidly obscure the line-of-sight pipe, thereby protecting the radiated experiments from debris damage.

The Fast Acting Closure (FAC) obscures the LOS when the approximately 450 pounds of high explosive wrapped on the outside diameter of the aluminum closure spool/plug is detonated. The 30 -inch inside diameter of the aluminum spool/plug is squeezed closed by the detonation forces.

A Gas Sealing Auxiliary Closure (GSAC), Modified Auxiliary Closure (MAC) or Stemming Anchor Closure (STAC) obscures the LOS when the two gates of the closure are propelled across the LOS opening from opposite directions. The expansion of high pressure $(\sim 15,500$ psi) helium gas propels the gates when the cylindrical gas reservoirs are opened with linear shaped explosive cutting charges.

\subsection{Document Purpose}

Due to the moratorium on nuclear weapons testing and with the likelihood that none of the current group of experts will be available to oversee the design, assembly, or installation of closures if testing recommences, it is imperative that the current knowledge base be accurately and thoroughly documented.

This document details the technology, fabrication, fielding, including operational, mothball and start-up procedures, safeguards and performance of the closures. It also serves as a "Road Map" indicating where to find additional information about the closures. Appendix A indexes the closure program documents stored in the NTS, Area 6, CP10 Warehouse.

This document will serve as the basic closures' reference if underground nuclear weapons effects testing resumes in the future. It indicates the location of the two FAC and two MAC closures that have been fabricated and stored, and Appendices $\mathrm{B}$ and $\mathrm{C}$ indicate the location of the hardware, equipment and instructions necessary to field and operate the closures. This document also indicates the location of the specifications, drawings, instructions, raw materials, hardware and the assembly and test equipment necessary to fabricate additional closures. 


\title{
2.0 Technology
}

\subsection{History}

Sandia has been involved in the development of numerous fast-acting closure systems for the underground testing program since the mid-1960s. Development of the Current FAC has evolved since around 1980. Development of the current generation of GSAC, MAC and STAC type auxiliary closures began in 1977.

\begin{abstract}
A Sandia report, History of Sandia National Laboratories' Auxiliary Closure Mechanisms ${ }^{1}$ gives a complete history of the underground testing program and describes how and why fast-acting closures have become an integral part of the containment for HLOS underground nuclear testbeds.
\end{abstract}

\subsection{Research and Development}

Development of the present closure systems has been an evolutionary process that emphasized continued improvement of the closures. Rarely was a FAC or GSAC an exact copy of its predecessor.

The recently fabricated FACs have one piece forged aluminum tubes instead of rolled and welded aluminum plate tubes. This change provides a stronger, more homogeneous closure spool and eliminates the risk of cracks forming in the weld heat affected zones. Since 1987, helium instead of nitrogen gas has been used to propel the auxiliary closure gates with an accompanying reduction in the auxiliary closure function times.

\subsection{Design}

\subsubsection{FAC}

The 30-inch FAC, shown in Figure 1, is an explosively driven containment device. The FAC consists of three aluminum tubes assembled concentrically to form an aluminum plug/closure spool that is bolted to a steel-transition flange and secured to the HLOS pipe. Approximately 450 pounds of high explosives are wrapped around the outside diameter of the aluminum tube assembly. The complete FAC assembly has a maximum diameter of about 6.5 feet, is about 11.5 feet long and weighs about 30 tons.

When the high explosives are detonated, the aluminum tubes are rapidly squeezed closed by the detonation forces. The closed FAC prevents nuclear test debris from passing through to the HLOS pipe on the portal side of the FAC. The FAC is designed to close the 30-inch inside diameter in 1 millisecond (ms) and to withstand ground shock loads of up to $3 \mathrm{kbar}$.

A Sandia report, Development of a Fast-Acting Closure for Use in an Underground Nuclear Testbed, ${ }^{2}$ gives a complete history of this closure's initial design and early development. 


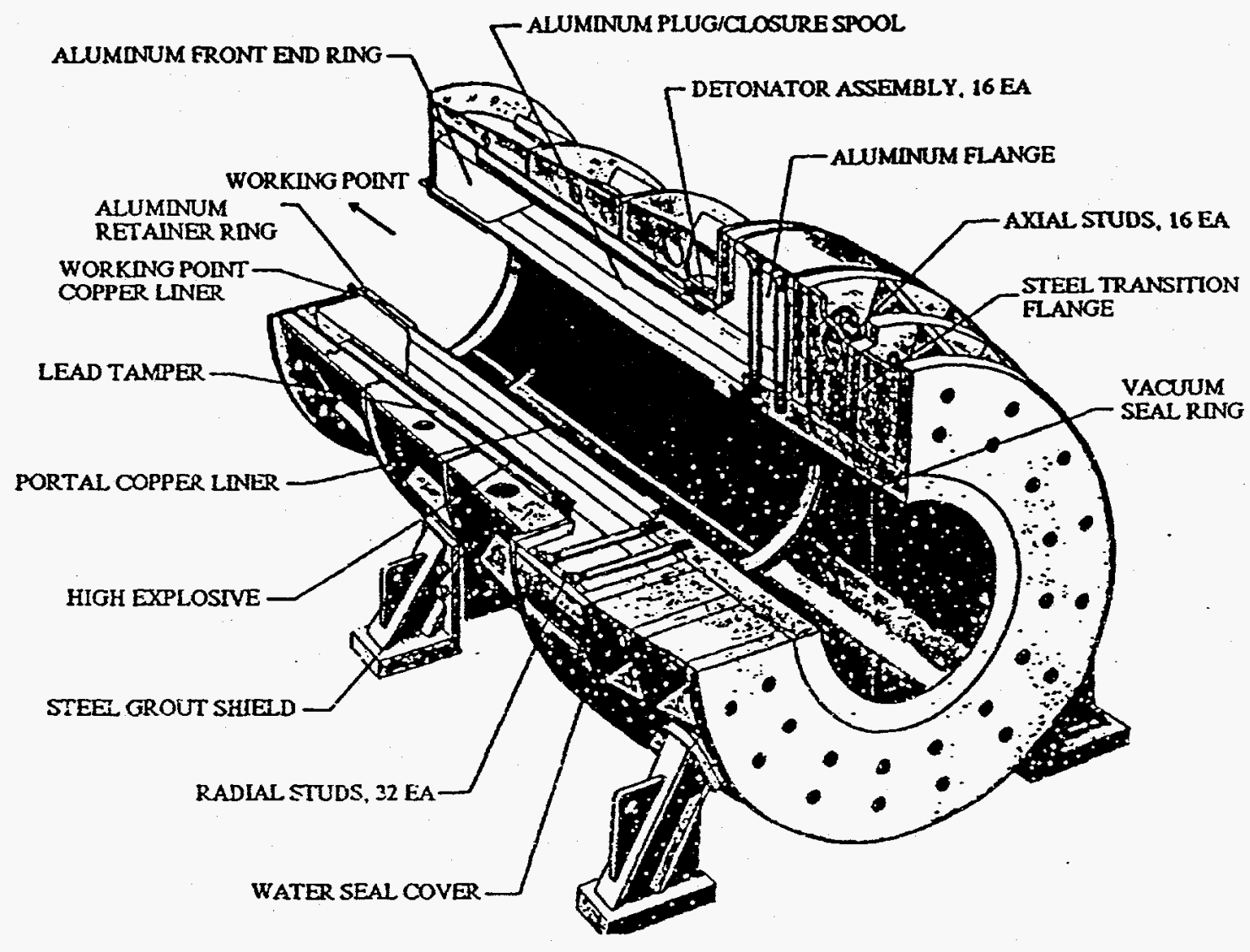

Figure 1. 30-inch Fast Acting Closure

\subsubsection{GSAC}

The 72-inch GSAC, shown in Figure 2, is basically a large, rectangular steel box containing two massive sliding gates that are propelled across the HLOS opening from opposite directions. The gates are 81 inches high, 12 inches thick, 85 and 94 inches long and weigh over 3 tons each. A 2.7 cubic foot cylindrical reservoir containing helium gas at 15,000 to 17,000 psi is located behind each gate at opposite ends of the housing. When the reservoirs are severed by linear shaped explosive cutting charges, the gates are driven into their overlapped, closed position. The gates are stopped by crushing high-density aluminum honeycomb blocks. Gate rebound is prevented by the gate's tapered steel mandrels jamming into cylindrical tubes anchored to the housing. Inertial wedge assemblies mounted on the inner face of the working point gate are activated when the gate decelerates. This wedge action forces the gates apart: the working point gate is forced into tight contact with the housing and the portal gate is crushed onto the ridges of the seal ring. A complete GSAC assembly is about 26.5 feet long, 8.5 feet high, 4 feet across and weighs about 48 tons.

The overlapped gates of a closed GSAC provide a barrier that prevents passage of the stemming materials and nuclear test debris that could damage or destroy the radiated experiments. The 72 -inch GSAC is designed to obscure the 72 -inch 
diameter LOS pipe in $18 \mathrm{~ms}$ and to be fully closed with completely overlapped gates in $33 \mathrm{~ms}$. The closed GSAC can withstand a static pressure load of up to 22,000 psi.

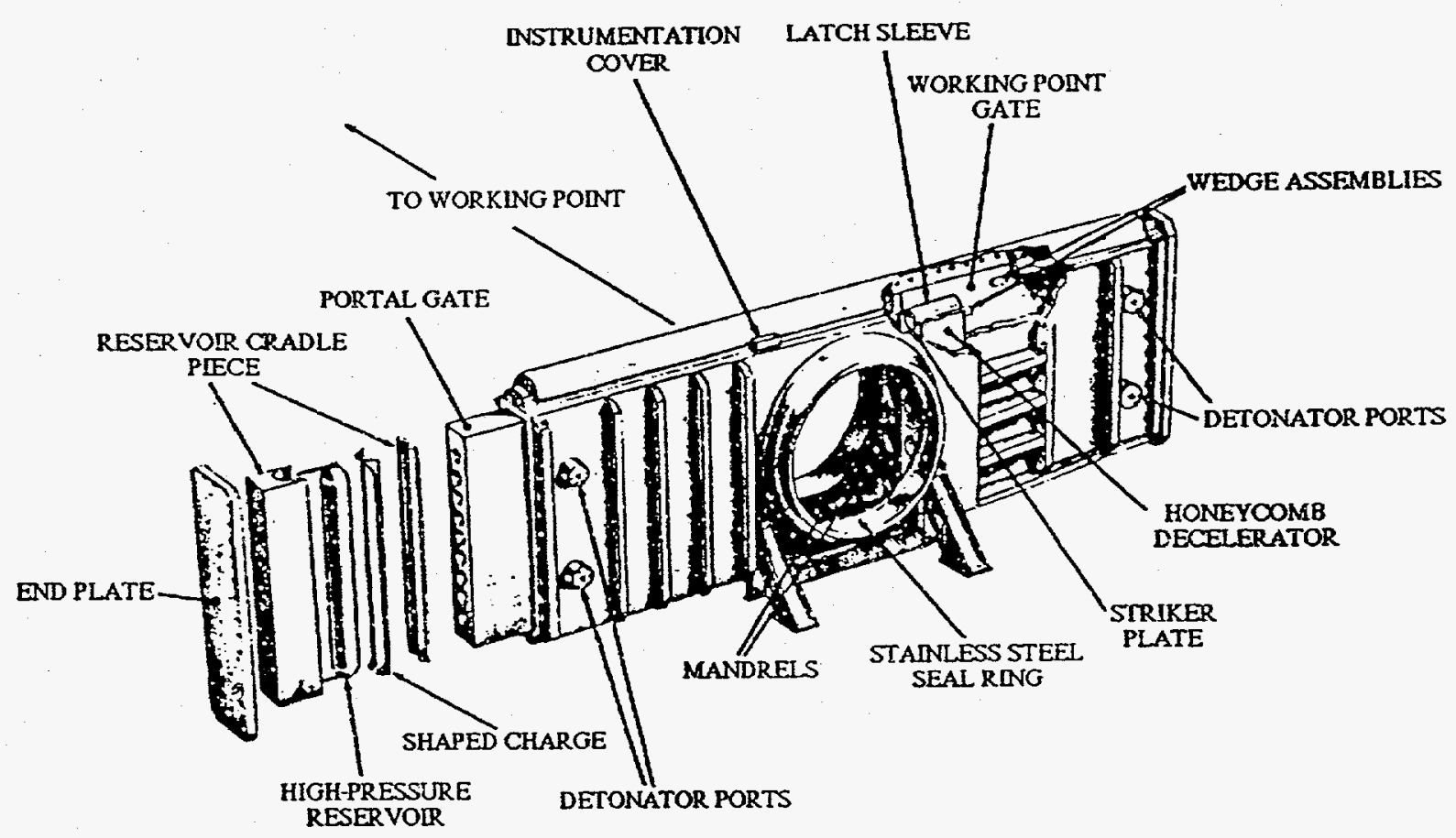

Figure 2. 72-inch Gas Sealing Auxiliary Closure

The design and operation of the auxiliary closures described below are similar to those of a GSAC.

\subsubsection{2" MAC}

Although the bore of the 72-inch MAC is the same size as the bore of the 72-inch GSAC, there are other differences that make the MAC a MAC and not a GSAC. Both gates are 81 inches high, 12 inches thick and 86 inches long, the reservoir cradles are 3 inches shorter and the working point gate standoff was eliminated. Consequently, the overall length of a MAC is about 2 feet shorter than the GSAC. The MAC does not have sealing features or wedge assemblies to force the gates apart. It does have a welded in, mild steel bore sleeve and gate spreader bars to force the gates against the housing sides. A complete MAC assembly is about 24.5 feet long, 8.5 feet high, 4 feet wide and weighs about 47 tons.

Two 72-inch MACs have been built, but neither has been installed in a testbed and operated. Obscuration time of the MAC is predicted to be $16 \mathrm{~ms}$, with full closure occurring at $32 \mathrm{~ms}$. And like the GSAC, a closed MAC can withstand a static pressure load of up to 22,000 psi. 


\subsubsection{2" MAC}

Since the advent of the GSAC and prior to the development of the FAC, a 62-inch MAC was always used in conjunction with a GSAC. A 62-inch MAC is simply a scaled down version of a 72-inch MAC having a 62-inch bore instead of a 72-inch bore. Each gate is 68 inches high, 12 inches thick, 70.5 inches long and weighs slightly over 3,600 pounds. A complete MAC assembly is nearly 22 feet long, about 7.5 feet tall, 4 feet wide and weighs about 33 tons.

The five 62-inch MACs used had an average obscuration time of $13.8 \mathrm{~ms}$ and an average full closure time of $25.2 \mathrm{~ms}$. A 62-inch MAC using helium as the propulsion gas could possibly reach obscuration in about $10.8 \mathrm{~ms}$ and full closure in about $19.3 \mathrm{~ms}$.

\subsubsection{0" STAC}

The 50-inch STAC is identical to the 62-inch MAC except for the smaller bore diameter resulting in a shorter overall length and the usage of strong composite gates. Each strong composite gate is 68 inches tall, 12 inches thick, 75 inches long and weighs 3 tons. The complete STAC assembly is almost 21 feet long, about 7.5 feet high, 4 feet wide and weighs about 34 tons.

The only STAC ever used obscured the LOS pipe in $12 \mathrm{~ms}$ and reached full closure in $20.7 \mathrm{~ms}$.

The Sandia report, History of Sandia National Laboratories' Auxiliary Closure Mechanisms, ${ }^{1}$ provides a detailed description of GSAC and similar auxiliary closures design, operation and performance.

\subsubsection{Other Closure Systems}

Several other closure concepts were investigated, some were tested using scale models and others were depicted on design layouts and/or fabrication drawings.

a. An 18-inch inside diameter FAC with a steel plug/closure spool was designed. Because of its smaller inside diameter this closure would operate faster and its steel tubes would make it stronger allowing it to be positioned closer to the nuclear device.

b. A 31-inch inside diameter Anti-Seepage Seal Valve containing spring boosted, gravity operated gates was devised. This device was to be positioned directly to portal of a 30-FAC and when operated would seal off the working point end of the LOS pipe and prevent long term gas leakage.

c. A pipe foam system was designed and tested using a 1/4 scale model. The proposed foam system would inject foam into the LOS pipe between the AntiSeepage Seal Valve and the FAC. The foam was intended to seal any cracks or openings in the LOS pipe, the valve or the FAC, thereby assisting in the prevention of long term gas leakage.

The Anti-Seepage Seal Valve and the pipe foam system were to be incorporated in the proposed testbed where the experiment chamber, the TAPS and the LOS pipe on the portal side of the MAC would be reused. The LOS pipe between 
the valve and the MAC and the expended MAC would be removed and a new device chamber, FAC, LOS pipe and MAC would be installed.

\subsection{Procurement}

\subsection{FAC}

The DNA Acquisition Management Office (FCA) managed procurement of the last two FACs and the forged aluminum tubes required for their fabrication. Sandia provided the fabrication drawings and specifications, and the Contracting Officer's Technical Representative (COTR) who technically monitored the FAC fabrication, inspection, assembly and testing. Sandia also provided the necessary test and assembly equipment and the support personnel to conduct the tests and perform the assembly operations. Procurement of all FACs prior to the last two was managed by Department 9333 utilizing the Sandia Procurement System.

A complete FAC is fabricated, assembled and tested by a commercial heavy equipment fabricator at his facility. The contractor is responsible for the procurement of the necessary raw materials, except for the forged aluminum tubes provided by Sandia or the DNA, and all the welding and machining. Sandia provides the contractor technical assistance during assembly and conducts the necessary QA testing. Except for the installation of its high explosives a FAC is delivered to the NTS ready to be installed underground.

Fabrication contracts are awarded to the lowest priced, qualified bidder responding to a Request For Quotation for a contract to fabricate hardware and provide services per Sandia drawings and specifications. All FACs have been produced by these three companies on separate occasions:

Allied Engineering and Production Company of Alameda, California

L\&F Industries of Huntington Park, CA

Wilcox Machine Company of Bell Gardens, CA

Total procurement time of a 30 " FAC, including the three months required to award the fabrication contract, is twelve months. The delivered to NTS cost of a FAC procured in 1992 was $\$ 428,000$.

\section{Specialized Material and Hardware Procurement}

Because the forged aluminum tubes require six to seven months to acquire and they must be available shortly after the FAC fabrication contract is awarded, procurement of the forged tubes should be initiated nine to ten months prior to the start of FAC fabrication. The last forged tubes were procured from Shultz Steel, Southgate, CA.

Procurement of the sole-sourced DuPont Detasheet high explosive should be initiated about the time the FAC fabrication contract is awarded. Then, when the FAC is delivered to NTS, the Detasheet will be available for immediate installation. 
The remaining specialized hardware, i.e., A\&F grout box, jack pedestals, screw and cap assemblies and instrumentation need only be available when the FAC is installed underground.

Procurement records, including purchase requisitions, fabrication contracts, drawings and specifications, of all the FACs produced are located as declared in the Closure Document Index, Appendix A.

\subsection{GSAC, MAC or STAC}

The FCA also managed the procurement of the last two MACs and the four aluminum gate forgings required for their fabrication. Sandia procured the specialized hardware and assemblies, i.e., high pressure reservoirs, explosive shaped charges, honeycomb decelerators, detonator assembly parts, etc. Sandia provided the fabrication drawings and specifications, and the COTR who technically monitored the MAC fabrication, inspection, assembly and testing. Sandia also provided the necessary test and assembly equipment and the support personnel to conduct the tests and perform the assembly operations. Procurement of all the auxiliary closures prior to the last two was managed by Department 9333.

An auxiliary closure is fabricated, assembled and tested by a commercial heavy equipment fabricator at his facility. The fabricator is responsible for the procurement of the necessary raw materials, except for the aluminum gate forgings and the aluminum reservoir cradle forgings provided by Sandia or the DNA, and all the welding and machining. When the closure is ready for final assembly, Sandia supplies the specialized hardware and assemblies, and the technical personnel to manage and perform the final assembly and QA testing operations. An auxiliary closure with linear shaped explosive cutting charges installed on the reservoirs is delivered to the NTS ready to be installed underground.

Except for a 62" MAC and a 72" GSAC fabricated by Mountain States Steel in Provo, Utah, all the auxiliary closures have been fabricated by one of the same three contractors that have fabricated all the FACs.

Total procurement time of an auxiliary closure, including the three months required to award the fabrication contract, is twelve months. The delivered to NTS cost of a 72" MAC and its associated specialized hardware and assemblies procured in 1992 was $\$ 575,000$. A $72 "$ GSAC would have cost an additional $\$ 50,000$ to $\$ 75,000$.

\section{Specialized Material, Hardware and Assemblies Procurement}

The aluminum gate forgings require six to seven months to acquire and they must be available for shipment to the closure fabricator immediately after the fabrication contract is awarded. Consequently, procurement of the gate forgings should be initiated nine to ten months prior to initiating the closure procurement. The last gate forgings were procured from Shultz Steel, Southgate, CA.

Procurement of the other specialized materials, including aluminum cradle forgings, steel for reservoir fabrication, and if a GSAC is being built, a stainless steel rolled ring forging from which a seal ring is machined and tungsten for inertial wedge fabrication, should be initiated seven to eight months before the closure procurement is started. 
Typically an inventory of gate forgings and specialized materials was maintained so procurement of an auxiliary closure could be initiated without regard for the long lead times required to acquire these items. Presently, the inventory includes enough materials to build at least one auxiliary closure of any type, GSAC, MAC or STAC. The inventory is located at the NTS, Area 6, CP10 Warehouse.

Sole-Sourced and Special Hardware and Assemblies: Because of their highly specialized technical characteristics and/or rigid fabrication specifications and inspection requirements the following items are procured on sole-source contracts from previously qualified manufacturers. The special hardware and assemblies are defined by Sandia fabrication drawings. Acquisition of these items should be initiated when preparation of the closure fabrication contract is started.

In order to ensure that auxiliary closure reservoirs meet special requirements they are obtained from two qualified reservoir fabricators, D-VELCO Mfg. of Arizona, Phoenix, AZ and Sun Country Industries Inc. of Albuquerque, NM. Both of these contractors have demonstrated their qualifications by fabricating reservoirs on competitive development contracts. Since 1986, when Sun Country was qualified, these two fabricators have competed for the opportunity to build reservoirs.

The honeycomb decelerator assemblies have been procured from Alcore Inc., formally American Cyanamid, of Havre De Grace, MD since 1971. The honeycomb configuration, material and fabrication processes are the result of an extensive development program conducted for Sandia.

The explosive shaped charge assemblies have been manufactured by Jet Research Center Inc. of Swannanoa, NC since 1971. The shaped charge configuration was also developed exclusively for Sandia.

The nonstandard rectangular and segmented Gask-O-Seals have been procured from Parker-Hannifin Corp. of Culver City, CA since 1979. Parker-Hannifin designed, built and retains the special tooling required to manufacture these uniquely configured seals.

Procurement of the remaining hardware, i.e., detonator housing parts and housing padlocks, high pressure valve box, high pressure tubing and fittings, microswitches, magnetic sensors, 12-pin feedthrough connectors, jack pedestals, screw and cap assemblies, Gask-O-Seals, o-rings and screws required to assemble and install an auxiliary closure should be initiated shortly after the fabrication contract is awarded. And, if a GSAC is being built wedge assemblies are required. A limited inventory of some of these items is located in the Area 6, CP10 Warehouse.

Procurement records, including purchase requisitions, fabrication contracts, drawings and specifications, of all the auxiliary closures produced since Mighty Oak are located as declared in the Closure Document Index, Appendix A.

\subsection{Fabrication}

\subsection{FAC}

In a preaward meeting with the potential FAC fabricator, review all drawings and specifications, verify that the potential fabricator has a certified QA Plan and that 
the FAC will be inspected in accordance with MIL-I-45208A, and verify that the fabricator's welders are certified to perform the required welding. Immediately after the FAC fabrication contract is awarded, the fabricator provides a performance schedule that will be updated monthly and Sandia provides the fabricator with an ample supply of full scale fabrication drawings. Within one month of the contract award, the contract specified DNA or Sandia supplied forged aluminum tubes are shipped to the fabricator. The remaining contract specified hardware, assembly and testing equipment is shipped to the fabricator when necessary.

The personnel to manage and perform the assembly, inspection and testing operations are provided by Sandia. Following is a list of the major activities that must be adequately performed in order to build a highly reliable FAC.

1. Prior to the heat shrink assembly operation, conduct a vacuum check on the inside and outside diameter machined, interior aluminum tube to verify its vacuum integrity.

2. A Sandia representative shall witness the heat shrink assembly operation of the three machined aluminum tubes.

3. A Sandia metallurgist shall confirm the hardness of the aluminum tube subassembly and the steel ring forging in the transition flange.

4. A Sandia inspector shall ultrasonically inspect all the critical welds on the shield housing, transition flange and outriggers to verify their structural integrity.

5. Verify that both copper liners and the aluminum retaining ring are properly installed.

6. Conduct a vacuum check on the vacuum seal ring to verify that the roll bonded joint is vacuum tight.

7. After the vacuum seal ring is welded into the plug assembly, conduct a vacuum integrity check on the plug assembly.

8. Check the vacuum integrity of the transition flange assembly ring forging.

9. Observe the fabricator's assembly procedures and perform the preliminary operations leading up to the installation and preloading of the axial and radial studs. Preload the studs using hydraulic stud tensioners in accordance with Sandia ES\&H SOP SP472249, Fast Acting Closure Stud Tensioning at the Fabricator's Plant and at the Nevada Test Site. During tensioning the structural integrity of the studs is monitored by Sandia acoustic emissions experts. Verify the correct preload has been applied to the studs using the ultrasonic bolt gage.

10. Perform those operations necessary to epoxy the aluminum ring to the aluminum plug assembly.

11. Ultrasonically inspect the critical welds on the trunnion mounting plates. 
12. Observe the fabricator's assembly procedures and perform all the necessary operations prior to and during installation of the shields and the shield housing.

13. Conduct a vacuum check to verify the vacuum integrity of the working point O-ring seals.

14. Install the trunnions and rig the FAC for lifting using the Sandia certified and supplied lifting equipment. Lift and rotate the FAC from the vertical to the horizontal position. Attach the outriggers to the FAC and set it on the shipping stands.

15. After the fabricator welds the vacuum seal ring to the stainless steel butter weld in the transition flange, conduct the final vacuum check to verify the FAC's vacuum tight integrity.

16. Prepare the FAC for shipping and ship it to the NTS.

Fabrication records, including detailed checklists, fabrication SOPs and fabrication, assembly and testing reports, for all the FACs produced are located as declared in the Closure Document Index, Appendix A.

\subsection{GSAC, MAC or STAC}

Within two weeks after the closure fabrication contract is awarded, a meeting is arranged at the fabricator's facility to review the drawings and specifications, review his fabrication processes and schedules, and to outline the assembly and testing procedures. Within the same two week period, an ample supply of original size fabrication drawings and the contract specified DNA or Sandia supplied raw materials are shipped to the fabricator. The remaining contract specified hardware, assembly and testing equipment is shipped to the fabricator when necessary.

Completion of these listed major activities results in a completely assembled and tested high quality auxiliary closure ready for installation underground.

1. The fabricator acquires raw materials and starts welding and machining the body halves and various other parts.

2. Work on the closure gates is initiated. They are rough machined, heat treated and then finish machined. If a STAC is being built, before final machining of the gates can be accomplished, the steel plates must be attached to the gate faces. The plates are attached using studs and nuts that are preloaded using a hydraulic stud tensioning system. Sandia personnel perform the stud tensioning operation using Sandia supplied equipment.

3. Because the cradle assemblies are early deliverables, generally 10-12 weeks before the closure final assembly starts, work on the cradles is started immediately. The cradles are rough machined, heat treated and then finish machined.

The finished cradle assemblies are shipped to the NTS where the reservoirs, procured on a separate contract, are inserted and the high pressure tubing stubs are attached. Then the reservoirs are subjected to a 19,000 psi nitrogen 
gas overpressure test and the reservoirs and the attached tubing stubs leak rate is evaluated. This testing is performed in accordance with the Sandia ES\&H SOP SP472479, Qualification Testing of Auxiliary Closure Reservoirs in the U12N.16 Drift, N-Tunnel, NTS. The reservoirs are also monitored by acoustic emissions experts during the overpressure test.

When testing is complete the reservoir/cradle assemblies are shipped back to the closure fabricator to be included in the closure final assembly.

4. After welding and machining of the individual body halves is complete, they are mated to form the closure body. As many as ninety studs with nuts and washers are used to attach the halves. The studs are given an extremely high preload using hydraulic stud tensioners. Sandia personnel perform the stud tensioning operation using Sandia supplied equipment.

The closure final assembly and testing starts when the closure fabricator has completed fabricating and machining all the necessary parts and all the Sandia supplied hardware and equipment is at his facility. The personnel to manage and perform the assembly and testing operations are provided by Sandia.

5. Conduct the preliminary vacuum check after converting the closure body to a vacuum chamber by attaching the necessary hardware, i.e., bore cover plates, end closure plates with Gask-O-Seals, instrumentation covers with Gask-OSeals and detonator housing parts. This vacuum check is conducted primarily to verify the leak-tight integrity of all the pressure containment welds and seal surfaces.

6. Install the mandrel assemblies and magnetic sensor pins in the closure gates. If a GSAC is being built, the wedge assemblies, acquired on a separate contract, must be installed in the working point gate.

7. Conduct a functional fit check to verify that each gate will slide freely through its respective body cavity for the full required length of travel. This check also verifies correct mandrel to latch sleeve alignment and gate motion instrumentation positioning.

8. Assemble the auxiliary closure. The assembly sequence may vary depending upon delivery of the linear explosive shaped cutting charges and the Sandia Project Leader's discretion.

a. Install the honeycomb decelerator assemblies, the striker plates and the decelerator retaining rings. If a GSAC is being built, install the stainless steel seal ring.

b. Install the microswitches and magnetic sensors.

c. Insert the gates, attach the cavity seals and the cradle segments, and then push the gate assemblies into the body to the point where the shaped charges are installed. Bond the shaped charge shock attenuators to the cradle segments.

d. Install the explosive shaped charges in accordance with the Sandia ES\&H SOP SP472652, Handling and Installation of Auxiliary Closure Shaped 
Charge Assemblies. Attach the reservoir/cradle assemblies and push the gate assemblies into the body. Attach the end closure plates with GaskO-Seals and preload the studs and nuts using the hydraulic stud tensioning equipment.

e. If a MAC is being built, attach the gate spreader bars and if a bore sleeve is required, the fabricator's welder should heliarc weld the sleeve in place.

f. Install the instrumentation covers with Gask-O-Seals, the detonator housing parts and the other hardware required to close off the body cavity for the ensuing vacuum and pressure tests.

g. If a bore sleeve is installed, conduct the bore sleeve internal pressure test to verify the sleeve's structural and weld leak tight integrity.

h. Conduct another vacuum leak check on the completely assembled closure.

i. Connect and pressure leak check the high pressure tubing manifold. After an overnight leak rate evaluation is completed, the high pressure tubing troughs are installed by the fabricator's welder.

j. Deliver the completely assembled and tested auxiliary closure to the NTS.

Fabrication records, including detailed checklists, fabrication SOPs and fabrication, assembly and testing reports for all the auxiliary closures produced since Mighty Oak are located as declared in the Closure Document Index, Appendix A.

\subsection{Fielding}

Although the DNA assumes ownership of the closures when they arrive at a tunnel portal, Sandia is responsible for the following closure fielding activities and related worker training. Sandia is totally responsible for the FAC high explosives installation prior to the FAC's delivery to the portal. Sandia oversees the REECo installation and alignment of both the FAC and auxiliary closures. Sandia supervises the REECo Fitter installation of the auxiliary closure's high pressure gas system tubing and is directly responsible for the gas system testing and operation. All closure instrumentation is provided, installed and data recorded or monitored by Sandia. On both the FAC and auxiliary closures, Sandia Arming and Firing personnel are responsible for detonator installation, firing systems testing and detonator firing systems certification.

\subsection{FAC}

The FAC arriving at NTS from the fabricator's plant is delivered directly to Building 2201 where the approximately 450 pound of high explosives is installed in accordance with Sandia ES\&H SOP SP471922, FAC High Explosive Installation and Final Assembly at NTS, FAC High Explosive Assembly Building. Following is an abbreviated list of the activities associated with the explosives installation. 
1. REECo riggers using only Sandia supplied lifting apparatus, lift and offload the FAC from the transport, rotate it from horizontal to vertical position, set it on a rail flatcar and push the flatcar into Building 2201 North High-Bay.

2. Position the work platform around the FAC and remove the FAC shield housing and shields.

3. Cut, weigh, clean and bond the high explosives to the FAC aluminum plug and install the foil switches and water level sensors.

4. Install the shields and the shield housing. Conduct a vacuum check to verify the working point $\mathrm{O}$-ring seal vacuum integrity.

5. Prepare and ship the loaded FAC to the event tunnel portal for immediate transport underground.

Well in advance of the FAC delivery to the event tunnel portal, the tunnel is checked and appropriately prepared so the FAC's underground movement and installation may be safe and not complicated by other tunnel operations.

1. Load the FAC onto the special FAC transport dollies and transport it underground to its predetermined location in the LOS pipe drift.

2. Align the FAC using the FAC hydraulic jack control system in accordance with Sandia ES\&H SOP SP472289, Alignment (FACJAC) System Operation. After the FAC is properly aligned, weld the jack screws and pedestals, and weld additional stabilizing members between the FAC outriggers and the invert bearing plates.

3. Establish a secured safety perimeter around the FAC alcove by erecting bulkheads and chain link fence barriers. Access to the FAC is gained through the lockable door in the FAC access drift bulkhead. Access to the FAC area is allowed for only absolutely necessary operations.

4. After a successful Mandatory Full Participation (MFP) run and the device insertion, the FAC's final instrumentation checks are made and its detonators are installed in accordance with the Sandia ES\&H SOP SP472144, Installation of (EBW) Detonators and/or Low Energy Squibs Into Line Of Sight Closures Used at NTS. Preparatory work on the FAC is now complete and the FAC alcove is grouted.

Copies of all documents pertaining to the above mentioned FAC activities, including detailed procedures checklists, the three mentioned SOPs, the installation procedures document IP933301, Installation Safety Procedures Associated With Sandia Designed Closures Underground At NTS and the FOD/DOD Job Procedure, Installation of the U12N.24 FAC, are located as declared in the Closure Document Index, Appendix A.

\subsection{GSAC, MAC or STAC}

The auxiliary closure arriving at NTS from the fabricator's plant is delivered directly to the event tunnel portal where it is offloaded and set on the special closure transport dolly. Well in advance of transporting the closure underground, 
the tunnel is checked and prepared so the closure installation may be safe and not complicated by other tunnel operations. Listed below are the major activities associated with installing an auxiliary closure underground.

1. Transport the closure underground to its predetermined location in the LOS pipe drift, rotate it 90 degrees and align the closure using four hydraulic jacks standing in adjustable bearing boxes that allow both axial and sideways movement. Then weld the mechanical jack screws and pedestals, and weld additional stabilizing members between the closure outrigger stands and the invert bearing plates.

2. After welding of the auxiliary closure to the LOS pipe is completed and the high pressure alcove is built, the high pressure tubing connecting the high pressure alcove pump facility, the closure and the valve box on the LOS pipe is installed and tested. This and all succeeding high pressure operations are conducted in accordance with Sandia ES\&H SOP SP472406, Installation and Operation of High Pressure Systems Used to Pressurize Auxiliary Closure Reservoirs.

3. Just prior to prestemming the auxiliary closure cavity, the final instrumentation connections are made and checked. And, the detonators are installed in accordance with Sandia ES\&H SOP SP472144, Installation of (EBW) Detonators and/or Low Energy Squibs Into Line Of Sight Closures Used at NTS.

4. After the closure cavity is grouted, the closure's high pressure system is checked to verify its leak tight integrity.

5. The closure is now prepared for the event final pressurization and operation.

Copies of all documents pertaining to the above mentioned auxiliary closure fielding operations, including detailed procedures, the two mentioned SOPs, the installation procedures document IP933301, Installation Safety Procedures Associated With Sandia Designed Closures Underground At NTS, the FOD/DOD Job Procedure, Pressurization Check of the U12N.24 GSAC High Pressure Lines and the FOD/DOD Job Procedure, Installation of the U12N.24 GSAC, are located as declared in the Closure Document Index, Appendix A.

\subsection{Operation}

At the time specified on the DNA's HLOS Pipe Button-up Punchlist, pressurize the auxiliary closure reservoirs to the Sandia prescribed closure operating pressure. The optimum pressure is determined by evaluating the performance of similar closures used in the past and making an educated prediction of how the closure revisions will effect performance at that pressure. The closure reservoir pressures are monitored in the Area 6, CP20, Monitor Room up to event time when the pressures should drop to zero.

The detonators on both the FAC and the auxiliary closure are armed as prescribed on the Final Button-up Punchlist and fired at event zero time. 


\subsection{Performance}

The FAC performance is determined by evaluating SANDUS recorded diagnostic data. Foil switches and/or fiber optic switches at the working point and portal ends of the high explosive indicate explosive burn time. Burn time for detonation is calculated to be about 224 microseconds and if the high explosives detonate the FAC will close. FAC closure may be verified by interpreting data from the fluid couple plate (FCP) gages on the LOS pipe on both the working point and portal sides of the FAC and the FCP gage mounted on the FAC high-strength concrete bulkhead.

The initial indication of auxiliary closure operation is when the closure reservoirs gas pressure drops to zero at event time. The closure's obscuration time, full closure time and gate velocities can be determined by evaluating the SANDUS recorded magnetic sensors time-displacement data.

Closure performance is recorded in informal reports, in Sandia Reports and in the DNA's experiment Preliminary Results Report and Project Officer's Report. Samples of these reports for the Hunters Trophy Event are located as declared in the Closure Document Index, Appendix A.

A performance summary of the closures use on past events is tabulated on Page 17 of the Sandia report, History of Sandia National Laboratories' Auxiliary Closure Mechanisms. ${ }^{1}$

\subsection{Mothball Procedures}

The two DNA procured 30" FACs built in 1992 at Allied Engineering \& Production Co., Alameda, CA are stored, along with the necessary lifting and handling equipment, in the REECo building 12-929 on the 12-01(P,T-Tunnel) Road. Explosives are not installed on either of the FACs. One FAC is being supported on the two special FAC transport dollies.

The two DNA procured 72" MACs built in 1993 at Wilcox Machine Co., Bell Gardens, CA are stored in the P-Tunnel, Distant Zenith LOS Drift. The linear explosive shaped cutting charges are installed on both of the MACs. The only key in existence to unlock the padlocks on the detonator port covers of either MAC is located in the top drawer of filing cabinet 1 in the Area 6, CP10 Warehouse. One MAC is resting on the closure transport dolly. The instrumentation and detonator junction boxes for these two MACs are stored in the Area 6, CP10 Warehouse.

All the remaining equipment and hardware necessary to assemble, install and operate closures has been accumulated, cataloged and stored inside or outside the Area 6, CP10 Warehouse. All the closure program documentation, i.e., assembly instructions, installation and operating procedures, check lists, Preliminary Hazard Assessments (PHA), ES\&H SOPs, drawings and specifications, copies of several of the reports mentioned in this document, etc. has also been gathered, cataloged and arranged in the filing cabinets in the Area 6, CP10 Warehouse.

Specific document, hardware and equipment locations are specified in Appendices $\mathrm{A}, \mathrm{B}$ and $\mathrm{C}$. 
Appendix A Closure Document Index

Appendix B FAC Equipment and Hardware Inventory

Appendix C Auxiliary Closure Equipment and Hardware Inventory

\subsection{Start-up Procedures}

If an underground test utilizing a 30" FAC and a $72^{\text {" }} \mathrm{MAC}$ is planned, a DNA generated Test Plan and supporting documentation will describe the event test-bed configuration and particularly the closures locations, invert bearing plate elevations, the high pressure alcove size and location, and the high pressure line bore hole. A Sandia generated Test Support Plan and Experiment Plan will describe the closures $A \& F$ requirements and the closures instrumentation support requirements including cables, alcoves, power, recording, etc.

Purchase the necessary amount, weight and thicknesses, of Dupont Detasheet high explosives and associated adhesives, tape, etc. to be installed on the FAC. If Dupont Detasheet is unavailable, Ensign Bickford's Primasheet 1000 is an alternate flexible sheet explosive. The required quantities are described in the A\&F documentation included in the Closure Document Index, Appendix A. Retrieve one of the FACs from its Building 12-929 storage and transport it to Building 2201 , or other appropriate facility if Building 2201 is not available, to have its high explosives installed.

After the FAC's high explosives are installed and the unit has been vacuum checked, transport the loaded FAC to the event tunnel. Transport the FAC underground to the LOS pipe drift, align it and prepare it for operation.

The above mentioned operations are outlined in FAC Fielding, Article 5.1 and detailed in the various installation instructions, procedures checklists and SOPs declared in Article 5.1.

If the planned test is going to be conducted in P-Tunnel, simply move one of the MACs stored there into the LOS pipe drift, otherwise transport the MAC to the event tunnel LOS pipe drift. Position and align the MAC, install and test the high pressure gas system and perform the remaining procedures necessary to prepare the MAC for operation.

The MAC installation procedures are outlined in GSAC, MAC or STAC Fielding, Article 5.2 and detailed in the various installation procedures, procedures checklists and SOPs declared in Article 5.2. 


\section{References}

The location of reference copies of these documents is declared in the Document Index, Appendix A.

1. John C. Weydert and Glenda M. Ponder, History of Sandia National Laboratories' Auxiliary Closure Mechanisms, Sandia National Laboratories, SAND92-1131, December 1993.

2. H. C. Walling and L. R. Hill, Development of a Fast-Acting Closure for Use in an Underground Nuclear Testbed, Sandia National Laboratories, SAND862907, September 1987. 


\section{Appendix A}

\section{Closure Document Index}

This Index lists the most pertinent closure documents that reside in the quick reference library (QRL) located in the top drawer of filing cabinet number one. The filing cabinets are located in the NTS, Area 6, CP10 Warehouse. The documents contained in the QRL pertain to general closure operations and procedures, such as SOPs, as opposed to event specific documents, i.e., the Hunters Trophy GSAC Fabrication Report, that are contained in the event specific project and QA files. The QRL also contains several applicable Sandia Reports and samples of pertinent event specific documents, such as the Hunters Trophy FAC Performance Report. Although some of the documents maybe outdated or cancelled, copies are included in the QRL for reference.

Event specific project and QA files and other documents are listed here purposely to indicate their locations for future reference.

Document Description /Location

1. History of Sandia National Laboratories' Auxiliary Closure Mechanisms, Sandia National Laboratories, SAND92-1131, December 1993. /QRL

2. Development of a Fast-Acting Closure for Use in an Underground Nuclear Testbed, Sandia National Laboratories, SAND86-2907, September 1987. /QRL

3. Preliminary Hazard Assessment (PHA) 30" Fast Acting Closure (FAC) Fabrication and Installation, PH472264. /QRL

4. PHA Action Plan, PH472264. /QRL

5. PHA 72" Modified Auxiliary Closure (MAC) Fabrication and Installation, PH473328. /QRL

6. PHA Action Plan, PH473328. /QRL

Documents 7 through 13 are Sandia ES\&H Activity Specific SOPs:

7. FAC High Explosive Installation and Final Assembly at NTS, FAC High Explosive Assembly Building, SP471922. /QRL

8. Installation of (EBW) Detonators and/or Low Energy Squibs Into Line Of Sight Closures at NTS, SP472144. /QRL

9. Fast Acting Closure Stud Tensioning at the Fabricator's Plant and at the Nevada Test Site, SP472249. /QRL

10. Alignment (FACJAC) System Operation, SP472289. /QRL

11. Installation and Operation of High Pressure Systems Used to Pressurize Auxiliary Closure Reservoirs, SP472406. /QRL 
12. Qualification Testing of Auxiliary Closure Reservoirs in the U12N.16 Drift, N-Tunnel, NTS, SP472479. /QRL

13. Handling and Installation of Auxiliary Closure Shaped Charge Assemblies, SP472652. /QRL

14. A\&F Documentation/QRL

15. FAC fabrication and installation, procedures and checklists. /QRL

16. Auxiliary closure fabrication and installation, procedures and checklists. /QRL

17. Installation Procedures, IP933301, Installation Safety Procedures Associated With Sandia Designed Closures Underground at NTS. /QRL

18. FOD/DOD Job Procedure, Installation of the U12N.24 FAC. /QRL

19. FOD/DOD Job Procedure, Installation of the U12N.24 GSAC. /QRL

20. FOD/DOD Job Procedure, Pressurization Check of the U12N.24 GSAC High Pressure Lines. /QRL

21. Excerpts from these Hunters Trophy documents that pertain to closures, Test Support Plan, Experiment Plan, Preliminary Results Report and The Projects Officer's report. /QRL

22. Hunters Trophy Fast Acting Closure (FAC) Design and Performance, Sandia National Laboratories, SAND93-0648, October 1993. /QRL

23. Hunters Trophy Gas Sealing Auxiliary Closure (GSAC) Design and Performance, Sandia National Laboratories, SAND94-1846, August 1994. $/ \mathrm{QRL}$

24. Mighty Uncle and Mineral Wagon, 30" FAC and 72" MAC project and QA files. Filing cabinet 1 , drawer 2

Note: These two FACs and two MACs are the ones stored at NTS.

25. Hunters Trophy $30^{\prime \prime} \mathrm{FAC}$ and $72^{\prime \prime} \mathrm{GSAC}$ project and QA files. /Filing cabinet 1 , drawer 3

26. Distant Zenith 30" FAC, 72" GSAC and 50" STAC project and QA files. /Filing cabinet 1 , drawer 4

27. Mineral Quarry $30^{\prime \prime} \mathrm{FAC}$ and $72^{\prime \prime}$ GSAC project and QA files. /Filing cabinet 1 , drawer 5

28. Disko Elm 30" FAC and 72" GSAC project and QA files. /Filing cabinet 1, drawer 5

29. Mission Cyber 30" FAC and 72" GSAC project and QA files. /Filing cabinet 2 , drawer 1 
30. Middle Note 30 " FAC and 72" GSAC project and QA files. /Filing cabinet 2, drawer 1

31. Mighty Oak 62" MAC and 72" GSAC project and QA files. /Filing cabinet 2, drawer 2

32. Misty Rain 62" MAC and 72" GSAC inspection reports. /Filing cabinet 2, drawer 2

33. Diamond Beech $30^{\prime \prime} \mathrm{FAC}$ and LOS Pipe project and QA files. /Filing cabinet 2 , drawer 2

34. Midnight Zephyr 30" FAC and earlier FAC research and development project files. /Filing cabinet 2, drawer 3

35. Auxiliary closure research and development files, i.e., body design, gate design, mandrel and latch sleeve design, honeycomb decelerator development, wedge assembly design, and explosive shaped charge development. /Filing cabinet 2 , drawers $4-5$

36. Auxiliary closure performance data for the Hunters Trophy, Distant Zenith, Mineral Quarry, Disko Elm, Mission Cyber, Middle Note, Mighty Oak, Misty Rain, Midas Myth, Huron Landing, Miners Iron, G-Tunnel Test and Diablo Hawk events. /Filing cabinet 3, drawer 1

37. Closure related projects, i.e., Scale Model Gate Testing, Honeycomb Crush Testing, Pipe Foam System, Mine Saw Project, Passive Pressure Gage Project, Gas Sampler Systems, Diamond Fortune project files, and The Millyard Fireball Photography Experiment project files. /Filing cabinet 3, drawers 2 - 3

38. The collection of closure " $B$ " size drawing books and full-scale drawing prints, event photographs, and video tapes is located in the storage cabinet. 


\section{Appendix B}

\section{FAC Equipment and Hardware Inventory}

Location: NTS, Area 6, CP10 Warehouse, Inside- CP10-I and Outside- CP10-O NTS, Area 12, Building 12-929 on the 12-01 (P,T-Tunnel) RoadBldg. 12-929

\section{Description /Location}

1. 8 ea Shipping Stands, dwg. \#S55043 /Bldg. 12-929

2. 2 ea Sub-Assembly Trunnions, dwg. \#S51753 (short, rusty) /CP10-O

3. 2 ea Final Assembly Trunnions, dwg. \#S64767 (long, white) /Bldg. 12-929

4. 2 ea Hook Assemblies, dwg. \#S50936, includes 2 ea 1.5" X 6' wire rope slings with thimbles, and 4 ea 1.5" shackles. /Bldg. 12-929

5. 1 ea FAC Strongback, dwg. \#S49000, with 1 ea 2" shackle. /Bldg. 12-929

6. 1 ea Shield Lifting Brace, dwg. \#S64859, includes 6 ea $1 / 2-13$ UNC X 1 " long bolts, and flat washers. /CP10-I

7. 1 ea Shield Lifting Eye, dwg. \#S64860, includes 2 ea .75" turnbuckles. /CP10-I

8. 1 ea Shield Housing Strongback, dwg. \#S84812, includes 4 ea 1" turnbuckles, and 1 ea $1.5^{\prime \prime}$ shackle. /CP10-I

9. 1 ea Adapter Plate for Shield Housing Strongback, dwg. \#S49853, includes 2 ea $1 "$ " X 3.5" long bolts, nuts, and washers. /CP10-I

10. 4 ea Trunnion Quick Release Pins, .5" diameter X 4.5" long. /CP10-I

11. 1 ea Plate, Cable Guide, dwg. \#S49848, includes 2 ea .75" X 2.5" long bolts, nuts, and washers. /CP10-I

12. 1 ea Double Line Winch Adapter, dwg. \#S83622/CP10-I

13. 1 ea WP Winch Adapter, dwg. \#S83066/CP10-I

14. 1 ea Cable Guide, WP Winch, dwg. \#R32474, includes 1 ea 1" X 4" long bolt and nut. /CP10-I

15. 1 ea WP Vacuum Blank-off Plate, dwg. \#R22519/Bldg 12-929

16. 1 ea Portal Vacuum Blank-off Plate, dwg. \#S52540 /Bldg. 12-929 
17. 1 ea Vacuum Blank-off Plate for WP end of the Transition Flange, includes spare O-rings. /CP10-I

18. 1 ea WP Seal Test Chamber, dwg. \#S64710, (red top hat) /Bldg. 12-929

19. 1 ea Split Ring Clamp for WP Seal Test Chamber, dwg. \#S73022 (3 pieces) /Bldg. 12-929

20. 3 ea Shield Housing Alignment Pins, dwg. \#S51684/CP10-I

21. 1 ea Stud Tensioning Gage, dwg. \#S97147, used to measure bolt length change. /CP10-I

22. 12 ea Socket Head Cap Screws for Trunnions, 1" UNC X 4.5" long, Grade 8 /Bldg. 12-929

23. 1 ea FAC Trunnion Load Test Fixture /CP10-O

24. 2 ea Stud Tensioner Tool Support Brackets /CP10-I

25. 14 ea Water Level Sensor parts required to assemble the 3 required FAC sensors. /located in the storage cabinet inside CP10.

26. 20 ea FAC Detonator Holders, Sleeves and Nuts, including mounting hardware. /CP10-I

27. 3 ea A\&F Grout Box, dwg. \#S64863/CP10-I

28. 4 ea FAC Leveling Trunnions /CP10-O

29. 1 ea Old Style Shield Lifting Brace /CP10-O

30. 1 ea FAC Portal Dolly, dwg. \#S89529/Bldg. 12-929

31. 1 ea FAC WP Dolly, dwg. \#S89520 /Bldg. 12-929

32. 2 ea Guide Pin, FAC WP Dolly, dwg. \#S66607 /CP10-I

33. 4 ea Guide Pin, FAC Portal Dolly, dwg. \#S66606 /CP10-I

34. 1 ea Template, FAC Portal Dolly Alignment, dwg. \#R32466 /CP10-O

35. 6 ea Hex Head Cap Screws and Bevel Washers, .75", to secure WP Dolly to the FAC. /Bldg. 12-929

36. 8 ea Hex Head Bolts, Grade 8, 2" to secure Portal Dolly to the FAC /Bldg. 12-929

37. 1 ea Plywood Go-Gage for FAC, dwg \#S66648/CP10-O

38. 1 ea FAC HE Work Platform, dwg. \#S54769 /Area 26, Outside Bldg. 2201 
39. 3 ea Electric Winch, $4000 \mathrm{lb}$. capacity, $110 \mathrm{VAC}$, with controls, Dayton \#4Z327 /CP10-I

40. 3 ea Shackles, 1" size /CP10-I

41. 2 ea Dynamometer, field service type, $4000 \mathrm{lb}$. capacity, McMasterCarr \#1360T24 /CP10-I

42. 1 ea Blank-off Plate, 6" ASA type, with Gask-O-Seal and mounting hardware, all steel. /Bldg. 12-929

43. 1 ea Stud Tensioner System, air operated hydraulic, for 2 " bolts, includes 1 pump, 2 tools, 3 hoses, 1 tee, 2 gages, and spare parts, EG\&G Sealol Pilgrim System. /CP10-I

44. 1 ea Digital Multimeter, Fluke Model 23 Warehouse \#8, GES Locker

45. 1 ea Power Supply, 0-25 VDC, Hewlett-Packard Model 6216B Warehouse \#8, GES Locker

46. 1 ea Digital Thermometer, Type K Omega model \#HH-99K/CP10-I

47. 8 ea Fisheye Level, circular type, McMaster-Carr model \#2198A86 /CP10-I

48. 3 ea FAC Tool Box containing misc. hand tools. /CP10-I

49. 2 ea Workmate, Black \& Decker /CP10-I

50. 3 ea Stools, wooden workbench /CP10-I

51. 8 ea Jack Pedestal, 2" thick base, dwg. \#R21024/CP10-O

52. 8 ea Screw and Cap Assembly, Templeton Kenly \#2BC-30-8 In cardboard barrels inside CP10.

53. 8 ea Shoulder Nut, Templeton Kenly \#2NS-25/In cardboard barrels inside CP10.

54. 1 ea Hydraulic Alignment System for FAC on WP Dolly, includes control box, hoses, jacks, and fittings. /Stored in 7 wooden boxes inside CP10.

55. 4 ea Foil Switches for HE /located in storage cabinet inside CP10.

56. 2 ea Thermocouple Gages for FAC /CP10-I

57. 2 ea Braided Ground Strap, 10 foot /CP10-I

58. 1 ea Scale to weigh FAC HE /CP10-I 
59. 2 ea Vacuum Pump Systems, includes mechanical and blower type pumps, used for leak testing a FAC /CP10-I 


\section{Appendix C \\ GSAC, MAC and STAC \\ Equipment, Hardware and Raw Materials Inventory}

Location: NTS, Area 6, CP10 Warehouse, Inside- CP10-I and Outside- CP10-O

Equipment:

Description /Location

1. 1 ea Stud tensioner /Items 1-5 are stored in two aluminum shipping boxes inside CP10.

2. 1 ea Stud tensioner

3. 1 ea Air/oil pump assembly

4. 1 ea Air/oil pump assembly

5. 1 lot Stud tensioner hydraulic hose and tensioner system spare parts.

6. 2 ea Three stage Haskel gas booster pump /CP10-I

$7 \quad 2$ ea Single stage Haskel gas booster pump /CP10-I

8. 1 ea $\quad H P$ reactor vessel /CP10-O

9. 1 ea HP reactor vessel /CP10-O

10. 2 ea Gas bottle rack manifold /CP10-I

11. 2 ea Decelerator assembly tool /Items 11 and 12 are in a wooden shipping box inside CP10.

121 ea Cylindricity gage, dwg. \#T67687

13. 2 ea Steel, bore blank-off plate /CP10-O

14. 2 ea Closure assembly platform, dwg. \#T67366/CP10-O

15. 1 ea $6 \mathrm{ft}$. aluminum platform ladder /CP10-O

16. 1 ea $\quad 8 \mathrm{ft}$. aluminum platform ladder $/ \mathrm{CP} 10-\mathrm{O}$

17. 1 lot Hydraulic gate jack assembly, electric pump w/hoses and various extension bars, ball lock pins, chains, etc. /In a blue shipping box inside CP10.

18. 4 ea Cradle shipping box /CP10-O 
19. 3 ea Blue shipping box /CP10-I

20. 1 lot Vacuum pump system, including a mechanical pump and a blower, a 10 foot long 4 " flexible hose and misc. vacuum fittings for leak checking auxiliary closures. /CP10-I

\section{Hardware:}

1. 1 ea $10.5^{\prime \prime}$ OD $\times 63^{\prime \prime} \lg$ fabricated HP reservoir /CP10-I

2. 1 ea $10.5^{\prime \prime}$ OD $\times 76^{\prime \prime} \lg$ fabricated HP reservoir /CP10-I

3. 1 lot Misc. 1/4" HP tubing, valves and fittings /Items 3-16 are located in the storage cabinet inside CP10.

4. 1 ea Segmented Gask-O-Seal, dwg. \#T66860

5. 4 ea Rectangular Gask-O-Seal. dwg. \#R22411

6. 8 ea 2" dia. Gask-O-seal, 6303-2

7. 20 ea 15" Detonator Cable, dwg. \#T66834-023

8. 20 ea Inner Sleeve, dwg. \#R22625

9. 18 ea Machined check valve, 2620T-6TT, dwg. \#T67686

10. 10 ea Microswitch, IEN1-S

11. 20 ea Magnetic Sensor, 304A

12. 8 ea 12 Pin Feedthrough Connector

13. 6 ea 20,000 psi. transducer, G831-301-20M

14. 8 ea CONAX packing gland, PG4

15. 9 ea CONAX packing gland, PG2

16. 7 ea TruSeal, TSE01-50

17. 8 ea Jack Pedestal, dwg. \#R21024 /CP10-O

18. 8 ea Screw \& Cap Assembly, Templeton Kenly \#2BC-30-8 /tems 18 and 19 are in cardboard barrels inside CP10.

19. 8 ea Shoulder Nut, Templeton Kenly \#2NS-25

20. 30 ea Internal Wrenching Bolt, 5/16-24UNF x 3.5" Ig, MS20005-26 Items $20-22$ are in the storage cabinet inside CP10.

21. 1 lot Misc. screws, bolts ant nuts 
22. 1 lot Misc. o-rings

Raw Material:

Reservoir material

1. 3 ea $37^{\prime \prime} \lg 4330 \mathrm{~V}$ steel bar /CP10-O

2. 2 ea $66.5^{\prime \prime} \lg 4330 \mathrm{~V}$ steel tube /CP10-O

3. 3 ea $53.5^{\prime \prime} \lg 4330 \mathrm{~V}$ steel tube /CP10-O

Gate forgings

4. 2 ea $97.5^{\prime \prime} \times 83.5^{\prime \prime} \times 12.5^{\prime \prime}, 7075-01$ aluminum forging $/ \mathrm{CP} 10-\mathrm{O}$

5. 2 ea $76.5^{\prime \prime} \times 69.5^{\prime \prime} \times 13^{\prime \prime}, 7175-01$ aluminum forging /CP10-O

Cradle forgings

6. 2 ea $83^{\prime \prime} \times 20^{\prime \prime} \times 12^{\prime \prime}, 6061-01$ aluminum forging /CP10-O

7. 3 ea $71^{\prime \prime} \times 20^{\prime \prime} \times 12^{\prime \prime}, 6061-01$ aluminum forging /CP10-O

Inertial wedge material

8. 14 ea Tungsten blocks /CP10-I

Seal ring forging

9. $\quad 1$ ea $75^{\prime \prime} \mathrm{OD} \times 71^{\prime \prime} \mathrm{ID} \times 3^{\prime \prime}, 17-4 \mathrm{PH}$ stainless steel ring forging /CP10-O 


\section{Distribution:}

1 Col. Harlan A. Lawson, FCDNA/FCT

1 Laurence J. Ashbaugh, FCDNA/FCNV

6 Roland Carnero, FCDNA/CETS (M)

1 B. Ristvet, FCDNA/FCTT

1 W. Summa, FCDNA/FCTT

1 MS1033 G. E. Staller, 6111

1 MS9731 $\quad$ L. R. Carrillo, 8283

1 MS1165 J. E. Powell, 9300

1 MS1158 J. D. Plimpton, 9301

1 MS1170 P. L. Nelson, 9305

1 MS1170 S. E. Dains, 9305

1 MS1158 S. R. Dolce, 9308

3 MS1159 A. J. Chabai, 9311

J. Banister

R. C. Bass

$1 \quad$ MS1159

W. H. Barrett, 9311

$1 \quad$ MS1159

$1 \quad$ MS1159

1 MS1159

1 MS1160

1 MS 1160

1 MS1160

1 MS1 169

1 MS1391

T. K. Bergstresser, 9311

L. R. Hill, 9311

C. W. Smith, 9311

K. M. Glibert, 9312

B. C. Bedeaux, 9312

F. Biggs, 9312

C. W. Cook, 9322

3 MS1391

1 MS1391

F. M. Raymond, 9331

R. C. Shear, 9331

$1 \quad$ MS1156

$1 \quad$ MS1156

10 MS1156

$3 \quad$ MS1156

$1 \quad$ MS1157

$1 \quad$ MS9018

$5 \quad$ MS0899

1 MS0619

10 MS0100

I. U. Gals, 9331

R. C. Shear, 9331

O. L. Burchett, 9333

C. R. Cherry, 9333

D. P. Shenk, 9333

J. C. Weydert, 9333

R. L. Peabody, 9333-1

Central Tech. Files, 8523

Technical Library, 7141

Technical Publications, 7151

Document Processing for DOE/OSTI, 7613-2 